\title{
Prediction of water scarcity situation of a region
}

\author{
Meiqi Song \\ School of electric power engineering, North China Electric Power University, Baoding 071000, \\ China.
}

987353464@qq.com

Keywords: Scarcity situation, Grey Verhulst, Curve Fitting

\begin{abstract}
Currently, one quarter of the world's population is experiencing water scarcity. In order to alleviate this situation, a prediction model which based on quadratic curve fit and the method of Grey Verhulst has been built. We used quadratic curve fit to forecast the comprehensive indicator and the per capital water supply and demand ratio. And the wastewater emissions are predicted by the method of Grey Verhulst. Through the prediction results of these three indicators, we can know what the water scarcity situation of a region, a country, or a city will be in the future. So we can take measures in advance and minimize adverse effects.
\end{abstract}

\section{Introduction}

The problem we discussed is basing on the problem E in 2016 ICM. According to the United Nations, about one quarter of the world's population is experiencing water scarcity. For what, so many measures had been taken by the government. When find out the problems, we can do something to minimize adverse effects. In contrast, if the problem can be found in advance, and to prevent, then the results will be more satisfactory.

Based on the consideration above, we build a prediction model to forecast the water scarcity situation of a region, a country, or a city. The data of Beijing in the last ten years is taken as an example. We select three factors, including the comprehensive final scores, the wastewater emissions and the per capital water supply and demand ratio, and decide to use the method of quadratic curve fit forecast the comprehensive indicator and the per capital water supply and demand ratio. The wastewater emissions are predicted using the method of Grey Verhulst.

\section{Prediction Model}

We select three indicators to forecast the water situation in 15 years. They are the comprehensive final scores, the wastewater emissions and the per capital water supply and demand ratio. Because of the special nature of the data in 2008, we ignore the influence it had made. By observing the curve of comprehensive indicator and the per capital water supply and demand ratio, the overall trends of it close to a quadratic curve. So we decided to use the method of quadratic curve fit forecast the comprehensive indicator and the per capital water supply and demand ratio.

For another indicator, the problem that predicted value is too small does not exist. So we use the method of Grey Verhulst ${ }^{[3]}$ to forecast the wastewater emissions.

\subsection{Quadratic Curve Fit}

First of all, define the objective function as

$$
y=a_{2} x^{2}+a_{1} x+a_{0}
$$

After getting rid of the special indicator in 2008, there are ten indicators which constitute the column matrix $Y$, the matrix $X$ is defined as a matrix of ten rows and three columns. The elements of this matrix are constituted by the year. And the matrix $A$ is the result we need to calculate.

So these three matrixes are

$$
Y=\left[\begin{array}{llllllllll}
y_{1} & y_{2} & y_{3} & y_{4} & y_{5} & y_{6} & y_{7} & y_{8} & y_{9} & y_{10}
\end{array}\right]^{T}
$$




$$
\begin{gathered}
X=\left[\begin{array}{ccc}
x_{1}{ }^{2} & x_{1} & 1 \\
x_{2}{ }^{2} & x_{2} & 1 \\
\vdots & \vdots & \vdots \\
x_{10}{ }^{2} & x_{10} & 1
\end{array}\right] \\
A=\left[\begin{array}{c}
a_{2} \\
a_{1} \\
a_{0}
\end{array}\right]
\end{gathered}
$$

The objective function can be expressed in the form of matrix multiplication that

$$
Y=X A \text {. }
$$

The solution formula of matrix $A$ is

Here is the data we need to build the model. ${ }^{[1,2]}$

$$
A=\left(X^{\mathrm{T}} X\right)^{-1} X^{\mathrm{T}} Y .
$$

Table 1 Indicators Data (2004--2014)

\begin{tabular}{cccc}
\hline Year & $\begin{array}{c}\text { Per Capital Water } \\
\text { Supply and } \\
\text { Demand Ratio } \\
\left(\mathrm{m}^{3} / \mathrm{p}\right)\end{array}$ & $\begin{array}{c}\text { Wastewater Emissions } \\
\left(10^{4} * \mathrm{~T}\right)\end{array}$ & $\begin{array}{c}\text { Comprehensive } \\
\text { final scores }\end{array}$ \\
\hline 2004 & 0.309 & 0.218 & 0.4141, \\
2005 & 0.336 & 0.230 & 0.4280 \\
2006 & 0.322 & 0.216 & 0.4193 \\
2007 & 0.342 & 0.230 & 0.4502 \\
2008 & 0.487 & 0.321 & 0.4998 \\
2009 & 0.308 & 0.167 & 0.4559 \\
2010 & 0.328 & 0.179 & 0.4738 \\
2011 & 0.373 & 0.187 & 0.5105 \\
2012 & 0.550 & 0.285 & 0.5478 \\
2013 & 0.341 & 0.173 & 0.5018 \\
2014 & 0.271 & 0.136 & 0.4849 \\
\hline
\end{tabular}

Then we gain the result that

$A=[0.218,0.23,0.216,0.23,0.321,0.167,0.179,0.187,0.285,0.173,0.136]^{\mathrm{T}}$

Thus, we can calculate the forecast matrix $Y$.

\subsection{The Method of Grey Verhulst}

Define $\chi^{(0)}$ as the primary data series, so we gain the formula that

$$
\chi^{(0)}=\left(\chi^{(0)}(1), \chi^{(0)}(2), \ldots, \chi^{(0)}(\mathrm{n})\right) .
$$

$\chi^{(1)}$ is the $1-\mathrm{AGO}$ of $\chi^{(0)}$, so that

$$
\chi^{(1)}=\left(\chi^{(1)}(1), \quad \chi^{(1)}(2), \ldots, \quad \chi^{(1)}(\mathrm{n})\right) .
$$

$\mathrm{Z}^{(1)}$ is the mean generating sequence of $\chi^{(1)}$, so that

And then we gain the Grey Verhulst model that

$$
Z^{(1)}=\left(Z^{(1)}(2), \quad Z^{(1)}(3), \ldots, Z^{(1)}(n)\right) .
$$

$$
\chi^{(0)}+\mathrm{a} Z^{(1)}=\mathrm{b}\left(Z^{(1)}\right)^{2} .
$$

The symbols ' $a$ ' and ' $b$ ' are the parameter. Time is defined as the symbol ' $t$ '. And the whitening equation of the Grey Verhulst model is that 


$$
\frac{d x^{(1)}}{d t}+a x^{(1)}=b\left(x^{(1)}\right)^{(2)}
$$

\section{Analyzing the Prediction Model}

\subsection{Strengths and Weaknesses}

The different prediction methods are taken to predict the total score and the various indicators, in order to better close to the actual situation. The forecast model is tested by historical data, and the forecast accuracy is better in the short term. But as time increases, the error may become larger. In addition, this method cannot fully reflect the internal mechanism.

\subsection{Sensitive Analysis}

In order to verify the robustness of the model, we analyze the sensitivity of each factor. The other indicator which has a certain impact to the sensitivity of the prediction model is wastewater discharge (the indicator measures the impact of production and life on the ecology, the size of the water resource consumption). And the changes of the rest of the indicators are small, even if they make disturbance, the impact on the overall index is not large.

\section{Conclusion}

The predicted results (2004-2014-2030) are shown below.

By analyzing the plots, we can draw the conclusions ${ }^{[4]}$ :

- Within 15 years of our forecast, the comprehensive indicator shows tendency of decrease. In other words, the degree of the comprehensive final score becomes smaller and smaller. And the water scarcity in Beijing becomes more and more serious.

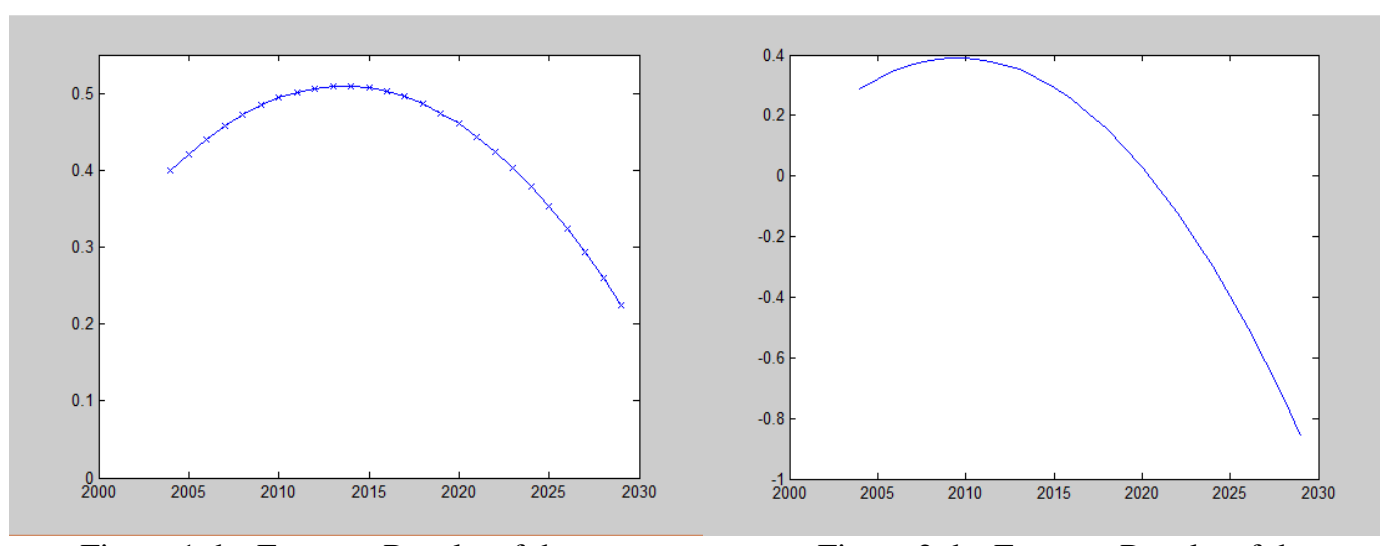
Figure 1 the Forecast Results of the
Figure 2 the Forecast Results of the Comprehensive Final Scores
Per Capital Water Supply and Demand Ratio

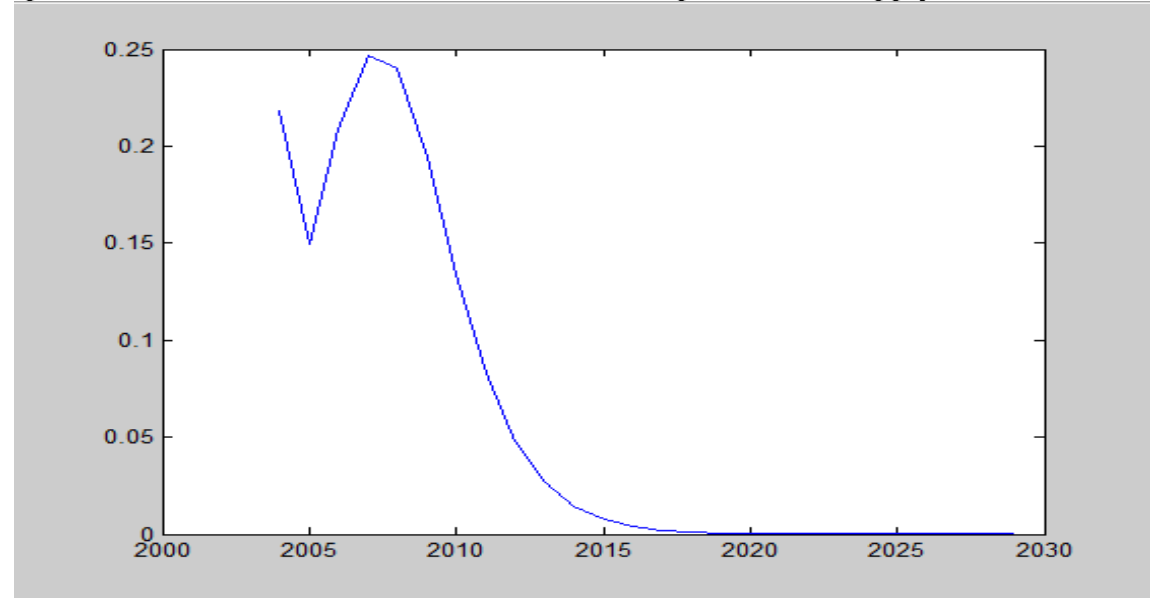

Figure 3 the Forecast Results of the Wastewater Emissions

- The final score of the per capital water supply and demand ratio in the next 15 years are 
decreasing, which means that per capital water consumption rate is Increasing.

- $\quad$ Both the per capital water resources and the per capital water consumption are decreasing, but the former is more rapid than the latter, which is the reason for the decreasing of the final score of the per capital water supply and demand ratio.

- The wastewater emissions are growing. That must lead to the result of environmental pollution.

- With the increasing of the wastewater emissions, the environment is significantly impacted by it. Sewage discharge into rivers, clean water is contaminated and it will reduce more rapidly. It will make ecological environment and people's quality of life more unfavorable.

\section{Reference}

[1] The UN water scarcity map http : // www. unep. Org / dewa / vital water /jpg / 0222 water stress - overuse -EN.jpg

[2] China Yearbookhttp://data.stats.gov.cn/search.htm?s=GDP

[3] Si Shoukui, Sun Xijing, Mathematical Modeling, National Defense Industry Press, 2015.

[4] Lei Liping, Study on Water Intervention Action Evaluation with Water Security Perspective, Huazhong University of Science and Technology, Wuhan, Hubei, 430074, P. R. China, May, 2012. 